\title{
RPRD1B promotes tumor growth by accelerating the cell cycle in endometrial cancer
}

\author{
YUAN WANG ${ }^{1}$, HAIFENG QIU ${ }^{2}$, WEIXU HU ${ }^{3}$, SHAORU LI $^{4}$ and JINJIN YU ${ }^{1}$ \\ ${ }^{1}$ Department of Obstetrics and Gynecology, The Affiliated Hospital of Jiangnan University and the Fourth People's \\ Hospital of Wuxi, Wuxi, Jiangsu 214062; ${ }^{2}$ Department of Obstetrics and Gynecology, International Peace Maternity \\ and Child Health Hospital of the China Welfare Institute Affiliated to Shanghai Jiaotong University, Shanghai 200030; \\ ${ }^{3}$ Department of Radiation Oncology, Zhongshan Hospital of Fudan University, Shanghai 200032; ${ }^{4}$ Department of Obstetrics \\ and Gynecology, The First Affiliated Hospital of Xinxiang Medical University, Weihui, Henan 453100, P.R. China
}

Received December 3, 2013; Accepted January 7, 2014

DOI: $10.3892 /$ or.2014.2990

\begin{abstract}
RPRD1B, the regulation of nuclear pre-mRNA domain containing $1 \mathrm{~B}$ gene, functions as a cell cycle manipulator and has been found overexpressed in a small panel of endometrial cancer types. In the present study, we investigated the roles of RPRD1B in endometrial cancer using various in vitro and in vivo experiments. According to our results, RPRD1B mRNA was significantly upregulated in endometrial cancer tissues $(\mathrm{P}=0.0012)$. RPRD1B overexpression was correlated with tumor stage $(\mathrm{P}=0.0004)$, histology type $(\mathrm{P}=0.0146)$ and depth of myometrial invasion $(\mathrm{P}=0.024)$. In vitro, $\mathrm{RPRD} 1 \mathrm{~B}$ promoted cellular proliferation $(\mathrm{P}=0.032$ for MTT assay and $\mathrm{P}=0.018$ for colony formation assay), and accelerated the cell cycle $(\mathrm{P}=0.007)$ by upregulating cyclin D1, CDK4 and CDK6, while knockdown of RPRD1B suppressed cellular proliferation $(\mathrm{P}=0.02$ for MTT assay and $\mathrm{P}=0.031$ for colony formation assay), and led to $\mathrm{G} 1$ phase arrest $(\mathrm{P}=0.025)$ through downregulating cyclin $\mathrm{D} 1, \mathrm{CDK} 4$ and CDK6. Consistently, in the nude mice model, RPRD1B overexpression significantly accelerated the tumor xenograft growth $(\mathrm{P}=0.0012)$, accompanied by elevated Ki-67 and cyclin D1. In addition, we demonstrated that downregulating RPRD1B could sensitize Ishikawa cells to Raloxifene $(\mathrm{P}=0.01)$. In summary, we demonstrated that RPRD1B was frequently overexpressed in human endometrial cancer. Both in vitro and in vivo, over-abundant RPRD1B could promote tumor growth and accelerate cellular cell cycle. In addition, knockdown of RPRD1B also increased cell sensitivity to Raloxifene, making RPRD1B a potent therapeutic target for
\end{abstract}

Correspondence to: Dr Jinjin Yu, Department of Obstetrics and Gynecology, The Affiliated Hospital of Jiangnan University and the Fourth People's Hospital of Wuxi, 200 Huihe Road, Binhu, Wuxi, Jiangsu 214062, P.R. China

E-mail: wxsyyujj@gmail.com

Key words: endometrial cancer, RPRD1B, cell proliferation, cell cycle, tumor growth endometrial cancer, particularly in patients with resistance to the selective ER modulators.

\section{Introduction}

During the past decades, the incidence of endometrial cancer has increased in most regions of the world (1-3). In 2013, there will be $\sim 49,500$ new cases and 8,200 deaths in the United States (4). However, our knowledge of the etiology of this disease remains poor.

Generally, endometrial cancer is grouped into type I (accounting for $80 \%$ of cases, primarily endometrioid adenocarcinoma, commonly linked to unopposed exposure to oestrogen, obesity and hormone receptor positivity) and type II (accounting for $<20 \%$ of cases, which consists of serous, clear cell and some undifferentiated tumors) (5-8). To date, the main treatments for endometrial cancer are surgery and/or radiation therapy, and for patients with late stage or distant metastasis, chemotherapy is also an option (9).

Unlike ovarian and cervical cancer, most endometrial cancer cases are localized in the uterus body, but lymphatic or vascular invasion rarely occur $(10,11)$. Molecularly, endometrial cancer is mainly characterized by uncontrolled cellular proliferation and unlimited cell cycle progression, a process in which these cell cycle-related proteins [such as cyclins and cyclin-dependent kinases (CDKs)] are strongly involved (9). This phenomenon suggested it may be a potent approach to inhibit the cell cycle in endometrial cancer, through targeting these cell cycle-related factors or their manipulators $(12,13)$. Recently, the RPRD1B gene was confirmed to be one of them, and can accelerate cell cycle by upregulating a panel of cyclins and CDKs (14).

RPRD1B, the regulation of nuclear pre-mRNA domain containing $1 \mathrm{~B}$ gene, is a human homolog of the Rtt103 gene (14); it can regulate the binding of RNA polymerase II to the CCND1 gene (cyclin D1) and prevent degradation of the CCND1 mRNA (15). Similarly, RPRD1B also enhances the transcription of many other cell cycle-related factors (such as CDK2, CDK4, CDK6 and cyclin E) (15). Given that elevated RPRD1B was reported in a small panel of endometrial cancer types, in the present study, we explored its detailed functions in endometrial cancer (14). 


\section{Materials and methods}

Tissue collection. Seventy-six endometrial cancer tissues were collected from patients who underwent surgery in our hospital from July 2010 to October 2012. The tumor stage and grade were determined following the criteria of Federation International of Gynecology and Obstetrics (FIGO, 2009) (16). Fifteen normal endometrium tissues were obtained as the control. Details given in Table I.

Immunohistochemical (IHC) staining. The IHC staining was performed as previously described (14). The primary antibodies used were: anti-Ki 67 (1:500; Wuhan Boster Biological Technology, Ltd., Wuhan, China) and anti-cyclin D1 (1:200; Cell Signaling Technology, Danvers, MA, USA). The staining was visualized using Histostain-Plus IHC kit (Shanghai Mingrui Biotech Co., Ltd., Shanghai, China). All slides were scored by two pathologists following these criteria: 0 , none (totally negative staining); 1 , weak (1-25\% positive); 2 , moderate ( $26-50 \%$ positive); 3 , strong ( $>50 \%$ positive).

Cell culture. Six endometrial cancer cell lines were used: Ishikawa, KLE, RL95-2, HEC-1B, SPEC-2 and AN3CA. All cells were purchased from the American Type Culture Collection (ATCC; Manassas, VA, USA) and maintained at $37^{\circ} \mathrm{C}$ in a humidified atmosphere of $5 \% \mathrm{CO}_{2}$. The medium was DMEM/F12+10\% fetal bovine serum (FBS) for KLE, SPEC-2 and RL95-2 and MEM +10\% FBS for Ishikawa, HEC-1B and AN3CA. The medium and the FBS were purchased from Gibco (Auckland, New Zealand).

$R N A$ isolation and quantitative real-time PCR. The tissue and cells were homogenized and total RNA was extracted using TRIzol (Invitrogen, Carlsbad, CA, USA). The mRNA expression of RPRD1B was measured by quantitative real-time PCR using SYBR-Green reaction mixture (Takara, Dalian, China). The primers for RPRD1B were: sense, 5'-ggatgctttttctcatgttgc-3' and antisense, 5'-cgccatacacacttcgttctt-3'. The reaction conditions were: $95^{\circ} \mathrm{C}$ for $30 \mathrm{sec}, 33$ cycles of $95^{\circ} \mathrm{C}$ for $5 \mathrm{sec}$ and $60^{\circ} \mathrm{C}$ for $32 \mathrm{sec} . \beta$-actin was used as the endogenous control. The relative expression of RPRD1B was calculated by the $2^{-\Delta \Delta C \mathrm{t}}$ method.

Western blot analysis. Total protein was extracted using the RIPA buffer (Wuhan Boster Biological Technology) and the concentration was determined by the BCA assay kit (Thermo Fisher Scientific, New York, NY, USA). Equal amount (30-50 $\mu \mathrm{g}$ ) of protein was separated on 12\% SDS-PAGE gel and transferred to the PVDF membrane (GE Healthcare, Buckinghamshire, UK). The membrane was then incubated with primary antibodies overnight at $4^{\circ} \mathrm{C}$ and with secondary antibodies for a further $1 \mathrm{~h}$ at room temperature. The bands were then developed using an imaging system. The primary antibodies for cyclin D1, CDK4 and CDK6 were purchased from Cell Signaling Technology and anti-RPRD1B mouse monoclonal antibody was obtained from Abgent (San Diego, CA, USA). $\beta$-actin was used as the endogenous control.

MTT assay. Ishikawa cells $\left(3 \times 10^{3}\right)$ or $5 \times 10^{3}$ HEC-1B cells/well were seeded into 96-well plates and incubated overnight. Then,
Table I. Relationship between RPRD1B expression and clinicopathological characteristics.

\begin{tabular}{lcc}
\hline Variables & Cases & Percentage \\
\hline Age (years) & & \\
$<55$ & 30 & 39.5 \\
$\geq 55$ & 46 & 60.5 \\
Pathological subtype & & \\
$\quad$ Endometrioid & 65 & 85.5 \\
$\quad$ Non-endometrioid & 11 & 14.5 \\
Stage & \\
I & & \\
II & 37 & 56.9 \\
III & 10 & 15.4 \\
IV & 15 & 23.1 \\
Grade & 3 & 4.6 \\
I & & \\
II & 26 & 40 \\
III & 21 & 32.3 \\
Myometrial invasion & & \\
$<1 / 2$ & 18 & 27.7 \\
$\geq 1 / 2$ & & \\
Lymph node metastasis & 23 & 62.7 \\
$\quad$ Negative & 14 & 37.3 \\
Positive & & \\
Lymphovascular space invasion & & 67.7 \\
Negative & 52 & 32.3 \\
Positive & 10 & 68.4 \\
\hline
\end{tabular}

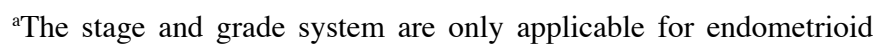
endometrial cancer. ${ }^{\text {b}}$ The analysis of myometrial invasion is only conducted in stage I cases.

the cells were transfected with pcDNA3.1-RPRD1B plasmid or siRNA-RPRD1B using Lipofectamine ${ }^{\circledR} 2000$ (Invitrogen) for $48 \mathrm{~h}$. Cells transfected with the scramble siRNA or the empty plasmid were set as the negative control. Then, $5 \mu \mathrm{l}$ MTT solution ( $5 \mathrm{mg} / \mathrm{ml}$; Sigma, Minneapolis, MN, USA) was added into the medium and incubated at $37^{\circ} \mathrm{C}$ for a further $1 \mathrm{~h}$. The formazan crystal was dissolved in $100 \mu 1$ DMSO (Sigma) and the absorbance was measured at $570 \mathrm{~nm}$ on a plate reader. These procedures were repeated in triplicate.

Colony formation assay. Then, $0.2 \times 10^{3}$ cells/well were plated into 6-well plates and transfected with siRNA-RPRD1B or pcDNA3.1-RPRD1B. The cells were routinely cultured for two weeks and the colony number was counted under an inverted microscope. This experiment was repeated in triplicate.

Cell cycle analysis. Briefly, $2 \times 10^{5}$ cells/well were seeded into 6 -well plates and incubated overnight. The cells were then transfected with siRNA-RPRD1B or pcDNA3.1-RPRD1B for $48 \mathrm{~h}$. The cells were harvested and resuspended in phosphatebuffered saline (PBS) and fixed in chilled $90 \%$ methanol 

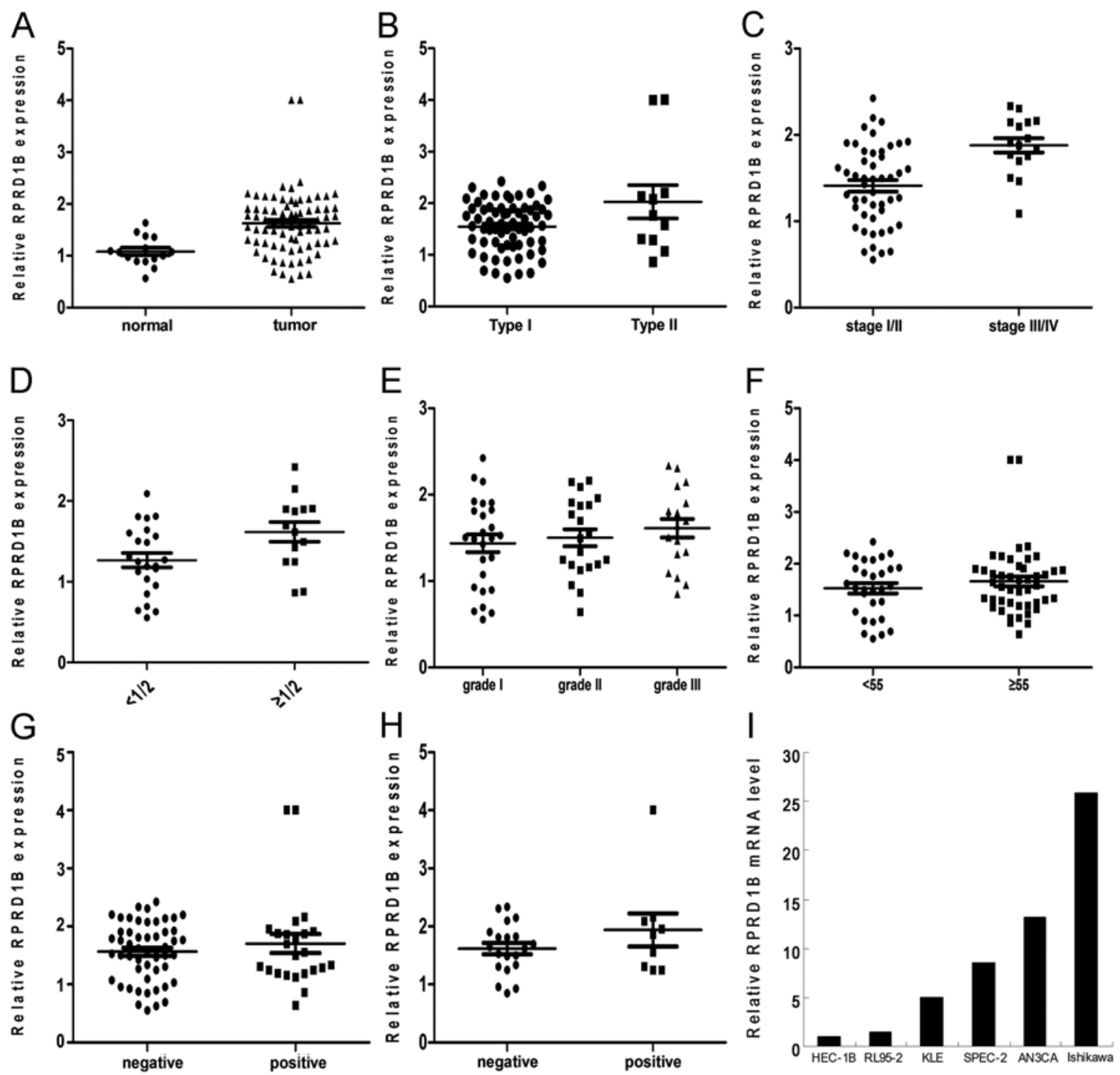

Figure 1. The mRNA of RPRD1B in human endometrial cancer. (A) RPRD1B expression in cancer tissues was much higher than that in normal endometrium $(\mathrm{P}=0.0012)$; (B) RPRD1B expression was much higher in type II endometrial cancer ( $\mathrm{P}=0.0146)$; (C) RPRD1B overexpression was related to late stage (stage III and IV, $\mathrm{P}=0.0004)$; (D) RPRD1B overexpression was related to the depth of myometrial invasion ( $\mathrm{P}=0.024)$; (E-H) RPRD1B overexpression was not related to patient age $(\mathrm{P}=0.3612)$, tumor grade $(\mathrm{P}=0.4503)$, lymphovascular space invasion $(\mathrm{P}=0.3559)$ or lymph node metastasis $(\mathrm{P}=0.1845)$; (I) the mRNA of RPRD1B in 6 human endometrial cancer cell lines.

at $-20^{\circ} \mathrm{C}$ for $24 \mathrm{~h}$. The cells were then resuspended in $1 \mathrm{ml}$ PI staining solution and analyzed on a FACSCalibur (BD Biosciences, Bedford, MA, USA).

Tumor growth assay. Five to six-week-old female severe combined immunodeficient mice (purchased from Shanghai SLAC Laboratory Animal Co., Ltd., Shanghai, China) were used for this assay. To establish the endometrial cancer model, $1 \times 10^{6}$ HEC-1B cells stably transfected with pcDNA3.1-RPRD1B were injected subcutaneously into the right flank of mice, and the control cells with empty plasmid were injected into the left flank. One week after injection, the tumor size was checked and recorded every other five days. The tumor volume $=$ (length $\mathrm{x}$ width $\left.^{2}\right) / 2$. Twenty-eight days after injection, all the mice were sacrificed and the tumor tissue was collected for further analysis.

Alterations of cellular sensitivity to Raloxifene. Raloxifene was dissolved in DMSO and diluted into different concentrations $(\mu \mathrm{M}): 0.01,0.1,1,10,20,40$ and 80 . The sensitivity of HEC-1B and Ishikawa cells to Raloxifene was determined by MTT assay.

Ethics statement. The present study was approved by the Human Investigation Ethics Committee of the Affiliated Hospital of Jiangnan University. Written informed consent was obtained from each patient involved in the present study. The animal research was carried out following the Guideline for the Care and Use of Laboratory Animals of China. The protocol was approved by the Committee on the Ethics of Animal Experiments of Jiangnan University [Permit Number: JSXK (hu) 2006-0088].

Statistical analysis. The statistical analysis was performed using SPSS 17.0 (SPSS Inc., Chicago, IL, USA). $\chi^{2}$ test or t-test was used for categorical and quantitative data appropriately. $\mathrm{P}<0.05$ was considered to indicate a statistically significant difference. 

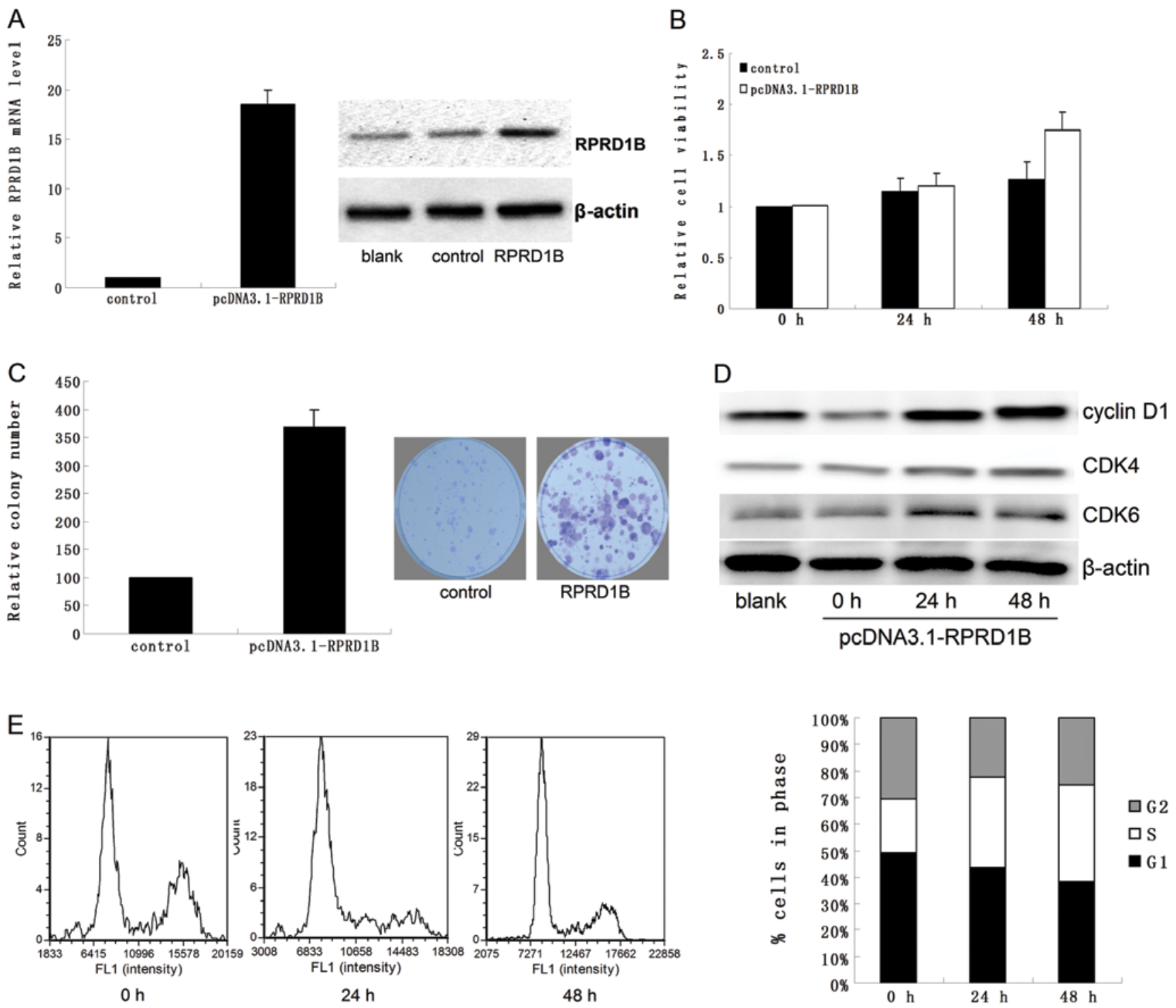

Figure 2. Upregulation of RPRD1B promotes cellular proliferation and accelerates the cell cycle in HEC-1B cells. (A) After 48-h transfection with pcDNA3.1RPRD1B, both the mRNA and protein levels of RPRD1B were significantly elevated; (B) HEC-1B cells with RPRD1B overexpression grew much faster than the control ( $\mathrm{P}=0.032)$; (C) RPRD1B overexpression also enabled cells to form more and larger colonies ( $\mathrm{P}=0.018)$; (D) RPRD1B upregulated cyclin D1, CDK4 and CDK6; (E) RPRD1B overexpression promoted HEC-1B cells into $\mathrm{S}$ phase ( $\mathrm{P}=0.018$ for $24 \mathrm{~h}$ and $\mathrm{P}=0.007$ for $48 \mathrm{~h}$ ).

\section{Results}

RPRDIB is frequently overexpressed in human endometrial cancer. RPRD1B mRNA was significantly overexpressed in endometrial cancer tissues, compared to the normal endometrium (Fig. 1A; $\mathrm{P}=0.0012$ ). By further analysis, we found that RPRD1B overexpression was correlated with histology type (Fig. 1B; $\mathrm{P}=0.0146$ ), tumor stage (Fig. $1 \mathrm{C} ; \mathrm{P}=0.0004$ ) and depth of myometrial invasion (Fig. 1D; $\mathrm{P}=0.024$ ), but was not associated with histology grade (Fig. 1E; $\mathrm{P}=0.3612$ ), patient age (Fig. 1F; $\mathrm{P}=0.4503)$, lymphovascular space invasion (LVSI; Fig. 1G; $\mathrm{P}=0.3559$ ) or lymph node metastasis (Fig. $1 \mathrm{H}$; $\mathrm{P}=0.1845$ ).

We then detected RPRD1B mRNA levels in these 6 endometrial cancer cell lines. As shown in Fig. 1I, RPRD1B mRNA was abundant in Ishikawa and AN3CA cells, but was only slight in HEC-1B and RL95-2.
Overexpression of RPRDIB promotes cellular proliferation and accelerates the cell cycle in HEC-1B cells. As shown in Fig. 2A, both the mRNA and protein of RPRD1B were upregulated following transfection with pcDNA3.1RPRD1B. Compared to the control, RPRD1B overexpression promoted cellular proliferation significantly (Fig. 2B and C; $\mathrm{P}=0.032$ for MTT assay and $\mathrm{P}=0.018$ for colony formation assay). In addition, RPRD1B also increased the expression of cyclin D1, CDK4 and CDK6 (Fig. 2D) and accelerated the cell cycle of HEC-1B cells (Fig. $2 \mathrm{E} ; \mathrm{P}=0.018$ for $24 \mathrm{~h}$ and $\mathrm{P}=0.007$ for $48 \mathrm{~h}$ ).

Downregulation of RPRDIB suppresses cellular proliferation and leads to cell cycle arrest in Ishikawa cells. Following treatment with siRNA-RPRD1B for $48 \mathrm{~h}$, both RPRD1B mRNA and protein were reduced significantly in Ishikawa cells (Fig. 3A). Loss of RPRD1B notably suppressed cellular 

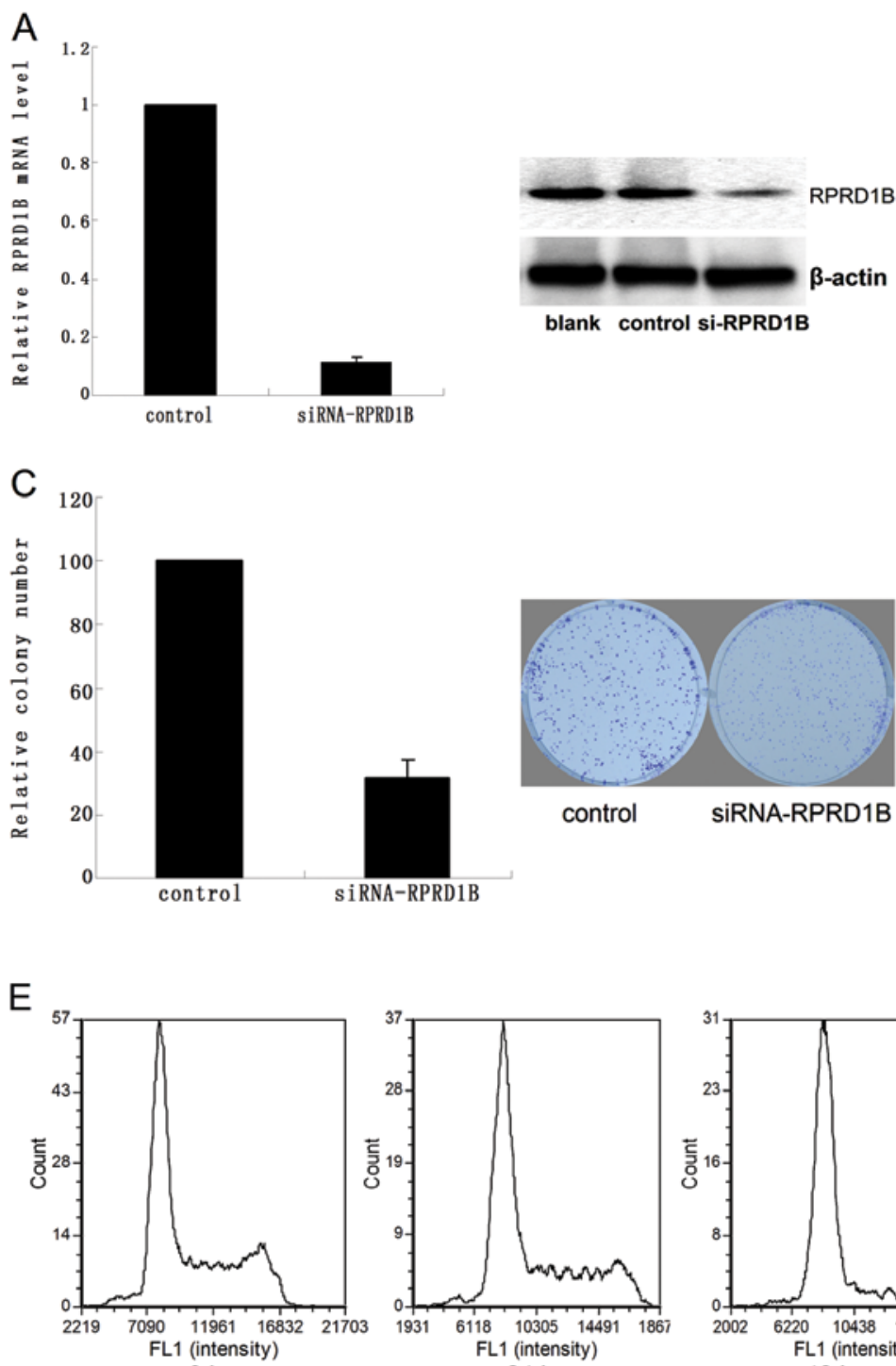

$\mathrm{Oh}$

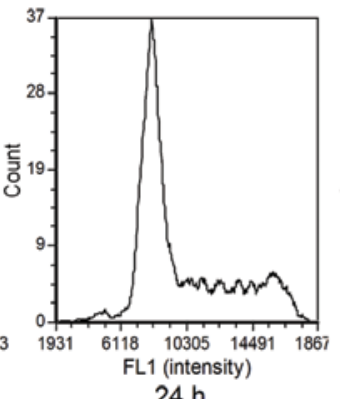

$24 \mathrm{~h}$

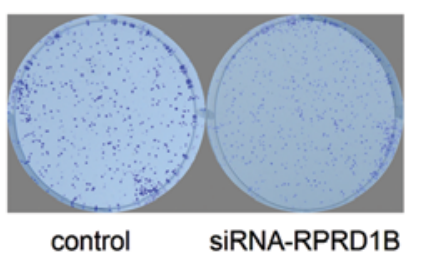

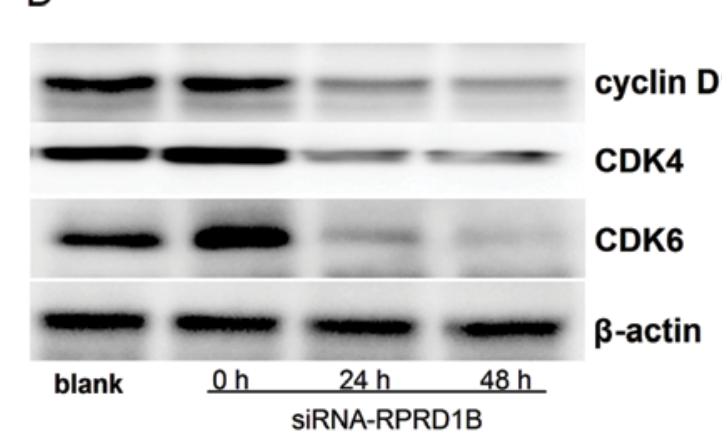

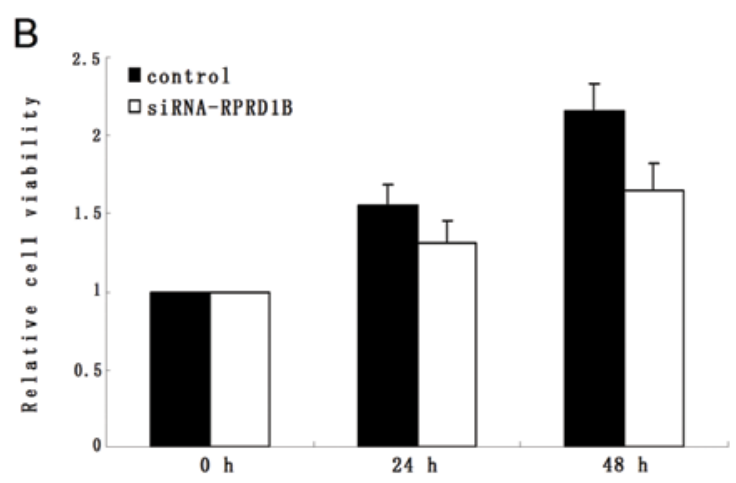

D

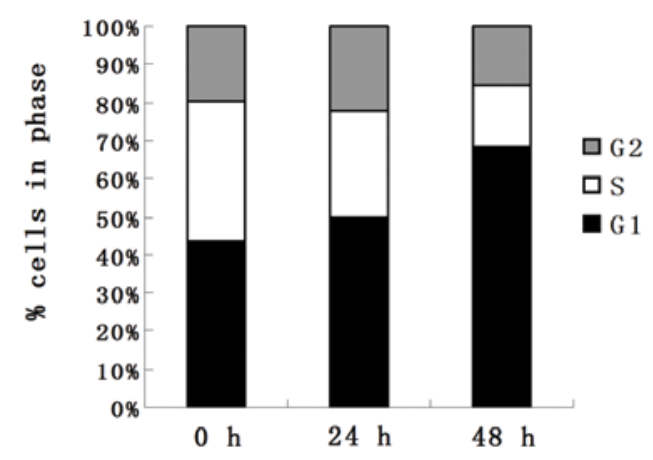

Figure 3. Downregulation of RPRD1B suppresses cellular proliferation and leads to cell cycle arrest in Ishikawa cells. (A) After 48-h transfection with siRNARPRD1B, both the mRNA and protein levels of RPRD1B were significantly downregulated; (B) Ishikawa cells with loss of RPRD1B grew much slower than the control $(\mathrm{P}=0.02)$; $(\mathrm{C})$ RPRD1B downregulation impaired the ability to form colonies in Ishikawa cells $(\mathrm{P}=0.031)$; $(\mathrm{D}) \mathrm{RPRD} 1 \mathrm{~B}$ downregulation decreased the expression of cyclin D1, CDK4 and CDK6; (E) RPRD1B downregulation led Ishikawa cells to G1 phase arrest ( $\mathrm{P}=0.039 \mathrm{for} 24 \mathrm{~h}$ and $\mathrm{P}=0.025 \mathrm{for} 48 \mathrm{~h}$ ).

proliferation (Fig. 3B and C; $\mathrm{P}=0.02$ for MTT assay and $\mathrm{P}=0.031$ for colony formation assay). Flow cytometry analysis showed that downregulation of RPRD1B inhibited the expression of cyclin D1, CDK4 and CDK6 (Fig. 3D), and led to G1 phase arrest at both 24 and $48 \mathrm{~h}$ (Fig. 3E; $\mathrm{P}=0.039$ for $24 \mathrm{~h}$ and $\mathrm{P}=0.025$ for $48 \mathrm{~h}$ ).

Overexpression of RPRDIB accelerates tumor growth in vivo. We established the endometrial cancer model by injecting HEC-1B cells (with or without overexpression of RPRD1B) into nude mice. According to our results, the xenograft with RPRD1B overexpression grew much faster than the control (Fig. 4A and B; $\mathrm{P}=0.0012$ ). We also found the tumor weight increased significantly following RPRD1B overexpression (Fig. 4C; $\mathrm{P}=0.007)$. By IHC staining, much higher expression of Ki-67 and cyclin D1 was detected in the group with overabundant RPRD1B (Fig. 4D).
Downregulation of RPRDIB sensitizes Ishikawa cells to Raloxifene. As shown in Fig. $5 \mathrm{~A}$, the $\mathrm{IC}_{50}$ of Raloxifene was $\sim 25 \mu \mathrm{M}$ for Ishikawa, but $>80 \mu \mathrm{M}$ for HEC-1B cells. Loss of RPRD1B increased the sensitivity of Ishikawa cells to Raloxifene (Fig. 5B; P=0.018); however, RPRD1B overexpression had no effects on the reactions of HEC-1B to Raloxifene (data not shown).

\section{Discussion}

Due to the high incidence rate and relatively favorable prognosis, endometrial cancer is now considered a chronic disease and, hence, preventing the tumor from unscheduled growth seems to be more appropriate. Dysregulated cell cycle is a common feature in nearly all types of human cancer $(17,18)$. To date, the relationship between cell cycle dysregulation and human cancer have been well documented. In particular, 
A
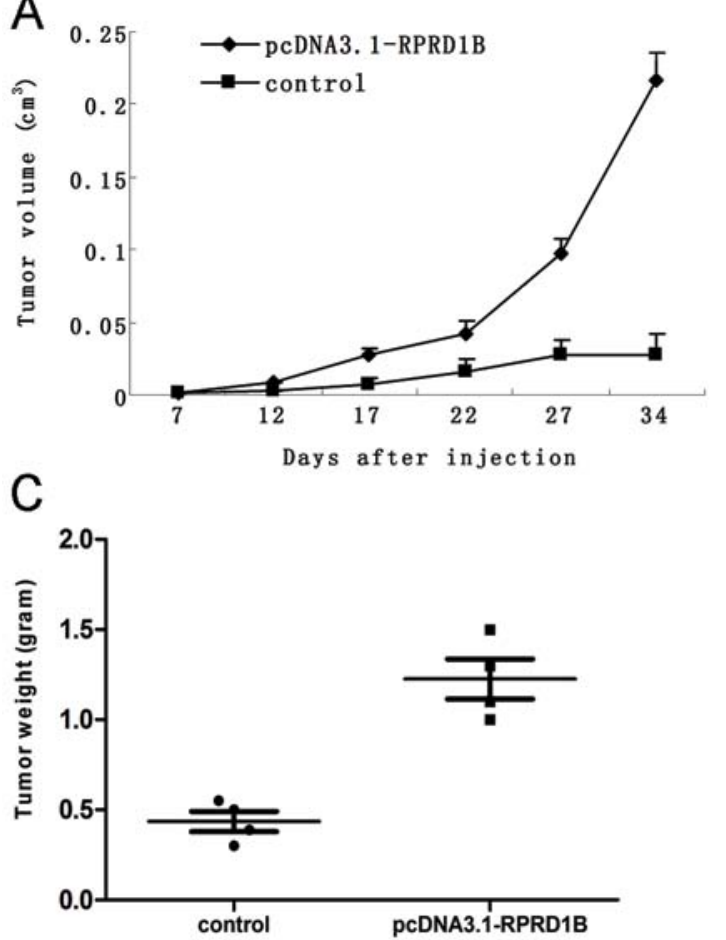

B

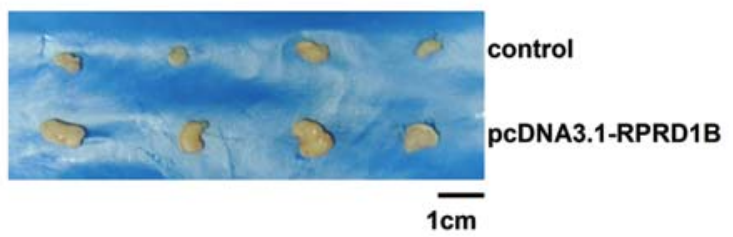

D

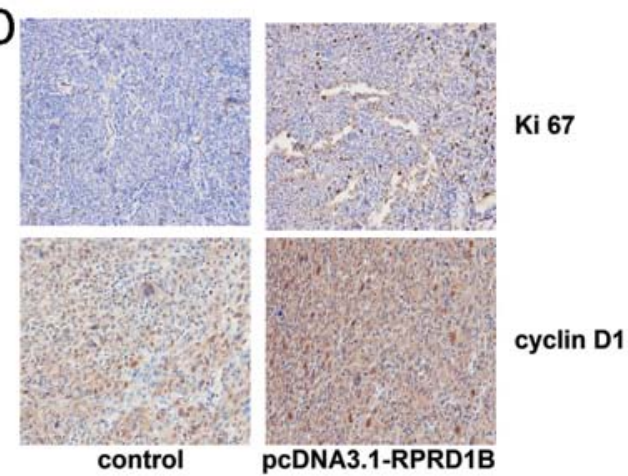

Figure 4. Overexpression of RPRD1B accelerates the tumor growth in vivo. (A and B) The tumor with RPRD1B overexpression grew much faster than the control ( $\mathrm{P}=0.0012)$; (C) the tumor weight increased significantly as RPRD1B was overexpressed ( $\mathrm{P}=0.007)$; (D) much stronger staining of Ki-67 and cyclin $\mathrm{D} 1$ was detected by IHC in the group with overabundant RPRD1B.
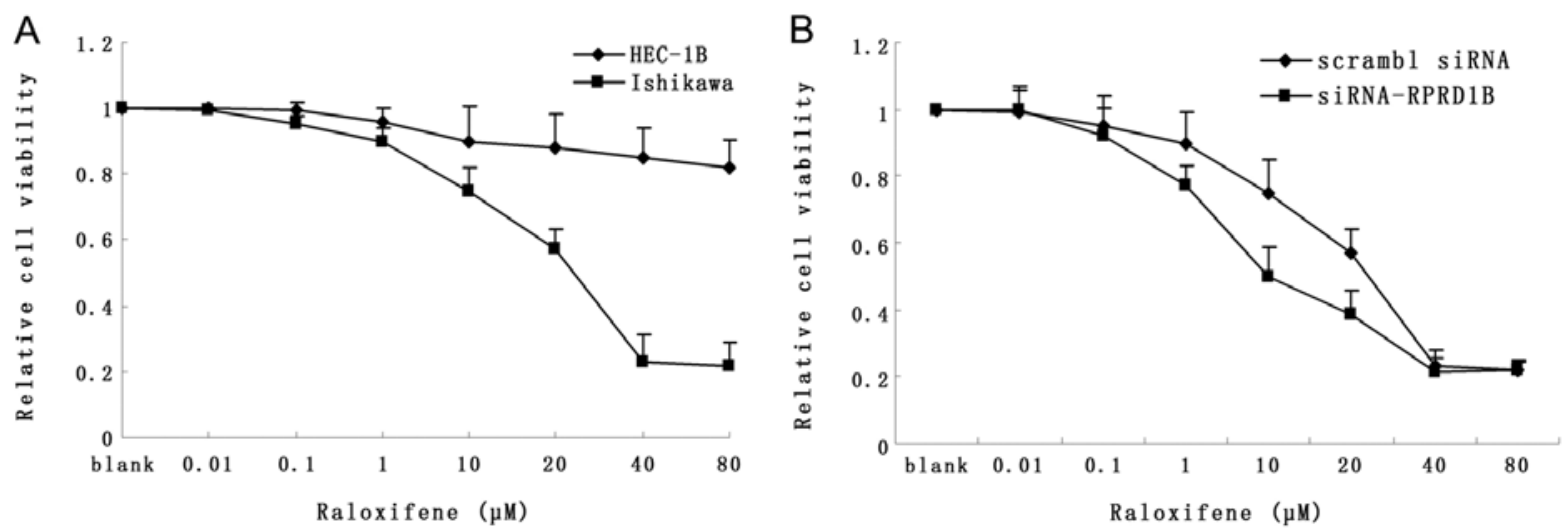

Figure 5. Downregulation of RPRD1B sensitizes Ishikawa cells to Raloxifene. (A) HEC-1B was resistant and Ishikawa was moderate sensitive to Raloxifene; (B) downregulation of RPRD1B sensitized Ishikawa cells to Raloxifene treatment $(\mathrm{P}=0.018)$.

several cell cycle regulators were confirmed to be critical for the initiation and progression of endometrial cancer (19-21).

In mammals, the cell cycle is manipulated by the cyclindependent kinases (CDKs), which can be activated by cyclins (such as cyclin D and E) and can be inhibited by Ink4 and Cip/ Kip inhibitors $(13,22,23)$. The activities of CDKs and their regulators are often dysregulated in human tumors owing to genetic or epigenetic changes or alterations of their upstream signal pathway (24-26). Recently, RPRD1B, a manipulator of both cyclins and CDKs, was found overexpressed in endometrial cancer (14). Therefore, we hypothesized that RPRD1B might be a key factor in endometrial neoplasia and development.

In the present study, we demonstrated RPRD1B overexpression in human endometrial cancer tissues, which was closely related with tumor stage, histology type and depth of myometrial invasion. In vitro, we explored the effects of RPRD1B on tumor cells by up- and downregulating its expression in two endometrial cancer cell lines. In HEC-1B cells, RPRD1B overexpression promoted cellular growth and accelerated the process of colony formation, while in Ishikawa cells, loss of RPRD1B inhibited its growth and colony formation.

As RPRD1B has been reported to be a regulator of cell cycle-related proteins, we then investigated the cell cycle status and expression of cyclin D1, CDK4 and CDK6 in the two cell lines. Compared to the control, RPRD1B overexpression promoted 2-fold more HEC-1B cells into the $\mathrm{S}$ phase, and the levels of cyclin D1, CDK4 and CDK6 were also upregulated. Moreover, RPRD1B downregulation inhibited the cell cycle 
and caused significant G1 phase arrest, through suppressing cyclin D1, CDK4 and CDK6. These findings were consistent with those of a previous study on gastric carcinoma cells (14).

Furthermore, we established the nude mice model to explore whether RPRD1B affects the tumor growth in vivo. As our data showed, HEC-1B cells with abundant RPRD1B grew much faster than the control group, and showed much stronger staining of Ki-67 (a proliferation index) and cyclin D1.

Considering that selective estrogen receptor modulators (SERMs) work well in a group of endometrial cancer patients but soon induced drug resistance in several cases, we then investigated whether RPRD1B could affect the sensitivity of Ishikawa and HEC-1B cells to Raloxifene $(27,28)$. We found that knockdown of RPRD1B could sensitize Ishikawa cells to Raloxifene, but overexpression of RPRD1B had no effects on HEC-1B cells. We hypothesized it could be caused by the different ER status of Ishikawa (ER positive) and HEC-1B (ER negative).

In summary, we demonstrated that RPRD1B was frequently overexpressed in human endometrial cancer. Both in vitro and in vivo, overabundant RPRD1B promoted tumor growth and accelerated cellular cell cycle through upregulating cyclin D1, CDK4 and CDK6, while knockdown of RPRD1B suppressed tumor growth and caused cell cycle arrest by decreasing cyclin D1, CDK4 and CDK6. In addition, knockdown of RPRD1B increased cells sensitivity to Raloxifene treatment. These findings may aid in the design of drugs targeting RPRD1B and its partners, which we believe will be a new strategy for curing this disease.

\section{Acknowledgements}

The present study was supported by grants to Jinjin Yu from Wuxi Science and Technology Bureau (no. CSE01N1113).

\section{References}

1. Wei KR, Chen WQ, Zhang SW, Zheng RS, Wang YN and Liang ZH: Epidemiology of uterine corpus cancer in some cancer registering areas of China from 2003-2007. Zhonghua Fu Chan Ke Za Zhi 47: 445-451, 2013 (In Chinese).

2. Jamison PM, Noone AM, Ries LA, Lee NC and Edwards BK Trends in endometrial cancer incidence by race and histology with a correction for the prevalence of hysterectomy, SEER 1992 to 2008. Cancer Epidemiol Biomarkers Prev 22: 233-241, 2013.

3. Bray F, Dos Santos Silva I, Moller H and Weiderpass E: Endometrial cancer incidence trends in Europe: underlying determinants and prospects for prevention. Cancer Epidemiol Biomarkers Prev 14: 1132-1142, 2005.

4. Siegel R, Naishadham D and Jemal A: Cancer statistics, 2013. CA Cancer J Clin 63: 11-30, 2013.

5. Hecht JL and Mutter GL: Molecular and pathologic aspects of endometrial carcinogenesis. J Clin Oncol 24: 4783-4791, 2006.

6. Dedes KJ, Wetterskog D, Ashworth A, Kaye SB and ReisFilho JS: Emerging therapeutic targets in endometrial cancer. Nat Rev Clin Oncol 8: 261-271, 2011.
7. Bokhman JV: Two pathogenetic types of endometrial carcinoma. Gynecol Oncol 15: 10-17, 1983.

8. Boruta DM II, Gehrig PA, Fader AN and Olawaiye AB Management of women with uterine papillary serous cancer: a Society of Gynecologic Oncology (SGO) review. Gynecol Oncol 115: 142-153, 2009.

9. Amant F, Moerman P, Neven P, Timmerman D, Van Limbergen E and Vergote I: Endometrial cancer. Lancet 366: 491-505, 2005.

10. Saso S, Chatterjee J, Georgiou E, Ditri AM, Smith JR and Ghaem-Maghami S: Endometrial cancer. BMJ 343: d3954, 2011.

11. Del Carmen MG, Boruta DM II and Schorge JO: Recurrent endometrial cancer. Clin Obstet Gynecol 54: 266-277, 2011.

12. Thanapprapasr D and Thanapprapasr K: Molecular therapy as a future strategy in endometrial cancer. Asian Pac J Cancer Prev 14: 3419-3423, 2013.

13. Malumbres M and Barbacid M: Cell cycle, CDKs and cancer: a changing paradigm. Nat Rev Cancer 9: 153-166, 2009.

14. Lu D, Wu Y, Wang Y, et al: CREPT accelerates tumorigenesis by regulating the transcription of cell-cycle-related genes. Cancer Cell 21: 92-104, 2012.

15. Ni Z, Olsen JB, Guo X, et al: Control of the RNA polymerase II phosphorylation state in promoter regions by CTD interaction domain-containing proteins RPRD1A and RPRD1B. Transcription 2: 237-242, 2011.

16. Creasman W: Revised FIGO staging for carcinoma of the endometrium. Int J Gynaecol Obstet 105: 109, 2009.

17. Kim JK and Diehl JA: Nuclear cyclin D1: an oncogenic driver in human cancer. J Cell Physiol 220: 292-296, 2009.

18. Massague J: G1 cell-cycle control and cancer. Nature 432: 298-306, 2004

19. Mitselou A, Ioachim E, Zagorianakou N, Kitsiou E, Vougiouklakis T and Agnantis NJ: Expression of the cell-cycle regulatory proteins (cyclins D1 and E) in endometrial carcinomas: correlations with hormone receptor status, proliferating indices, tumor suppressor gene products ( $553, \mathrm{pRb})$, and clinicopathological parameters. Eur J Gynaecol Oncol 25: 719-724, 2004.

20. Semczuk A and Jakowicki JA: Alterations of pRb1-cyclin D1-cdk4/6-p16(INK4A) pathway in endometrial carcinogenesis. Cancer Lett 203: 1-12, 2004.

21. Horree N, van Diest PJ, Sie-Go DM and Heintz AP: The invasive front in endometrial carcinoma: higher proliferation and associated derailment of cell cycle regulators. Hum Pathol 38: 1232-1238, 2007.

22. Ortega S, Malumbres M and Barbacid M: Cyclin D-dependent kinases, INK4 inhibitors and cancer. Biochim Biophys Acta 1602: 73-87, 2002.

23. Martin A, Odajima J, Hunt SL, et al: Cdk2 is dispensable for cell cycle inhibition and tumor suppression mediated by $\mathrm{p} 27^{\mathrm{Kipl}}$ and p21 ${ }^{\text {Cip1 }}$. Cancer Cell 7: 591-598, 2005.

24. Lundberg AS and Weinberg RA: Functional inactivation of the retinoblastoma protein requires sequential modification by at least two distinct cyclin-cdk complexes. Mol Cell Biol 18: 753-761, 1998.

25. Rane SG, Dubus P, Mettus RV, et al: Loss of Cdk4 expression causes insulin-deficient diabetes and Cdk4 activation results in $\beta$-islet cell hyperplasia. Nat Genet 22: 44-52, 1999.

26. Rosu-Myles M, Taylor BJ and Wolff L: Loss of the tumor suppressor p15Ink4b enhances myeloid progenitor formation from common myeloid progenitors. Exp Hematol 35: 394-406, 2007.

27. Brzozowski AM, Pike AC, Dauter Z, et al: Molecular basis of agonism and antagonism in the oestrogen receptor. Nature 389: 753-758, 1997.

28. Maximov PY, Lee TM and Jordan VC: The discovery and development of selective estrogen receptor modulators (SERMs) for clinical practice. Curr Clin Pharmacol 8: 135-155, 2013. 